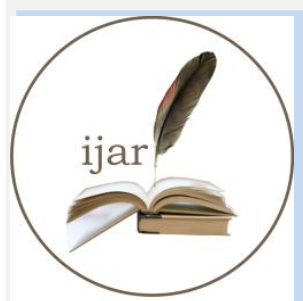

ISSN NO. 2320-5407
Journal Homepage: - www.journalijar.com INTERNATIONAL JOURNAL OF ADVANCED RESEARCH (IJAR)

Article DOI: $10.21474 /$ IJAR01/1425

DOI URL: http://dx.doi.org/10.21474/IJAR01/1425
INTERNATIONAL JOURNAL OF ADVANCED RESEARCH (JJAR)

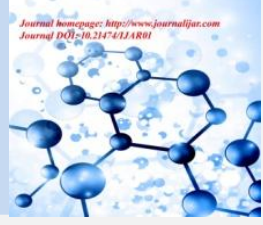

RESEARCH ARTICLE

\title{
FATIGUE AND SLEEP PROBLEMS AMONG AIRLINE CREW MEMBERS" FOR CONSIDERATION FOR PUBLICATION IN ARCHIVES OF INTERNAL MEDICINE PLUS FAMILY MEDICINE.
}

Dr alharbi abdulrhman obaid and Dr Etain mohammed.

\section{Manuscript Info}

\section{Manuscript History}

Received: 12 June 2016

Final Accepted: 19 July 2016

Published: August 2016

Key words:-

Airline, pilots, aircrew, fatigue, sleep

\section{Abstract}

Objectives:- The objectives of the study are to assess the level of fatigue, the presence of sleep disorders and addiction among commercial airline crew members. The study further explores to identify various health related symptoms among commercial airline crew members.

Methods:- It is a cross sectional study done from January to October 2014 on 108 airline crew members of Pakistan. A snow ball sampling method was used to administer a self reported questionnaire to involveduring a airplane flight. The questionnaire measures fatigue, insomnia and day time sleepiness by using Fatigue Severity Scale, Insomnia Severity Index and Epiworth Sleepiness Scale respectively. Data collected was analysed with SPSS version 20. All ethical considerations were taken in to account for the study.

Results:-Out of the total 108 respondents 86 were female 22 were male crew members. The mean age was $32.41 \pm 7.0$ years (Range 20 to 52 years). The majority were married (57\%) and had 1-10 years of work experience $(66 \%)$. The average flying hours per week was found to be $26.81 \pm 13.1$ hours. Fatigue was found to be clinically significant in $54 \%$ of the respondents while using insomnia severity index score $51.9 \%$ showed sub threshold insomnia,31.5\% showed clinically significant insomnia (moderate) and $7.4 \%$ had complains of severe clinically significant insomnia.Day time sleepiness was assessed and $82 \%$ respondents reported excessive increase in daytime sleepiness. In order to increase alertness $51 \%$ use caffeinated drinks, $27 \%$ used napping pre/after flight, $31 \%$ napping during flight, $17 \%$ taking stimulants for alertness, $5 \%$ caffeine supplements whereas $6 \%$ used hypnotic drugs. Forty eight percent were regular and occasional smokers while and only $8 \%$ were in habit of consuming alcohol regularly

Conclusion:-The present study shows that aircrew fatigue has become a reality in Pakistan's commercial airlines. The consequences results in a larger proportion with insomnia and day time sleepiness. More details data is required and careful monitoring is needed by the relevant administration 


\section{Introduction:-}

It took Christopher Columbus more than 2 months to reach America by sea in 1942.Since first flight of Wright Brothers in 1903 and the real take-off of commercial aviation in 1950s it's now hard to imagine tourism, trade, outmigration, immigration and even war without Air Travel. Air Travel is now acknowledged as the swiftest form of transportation in modern era. But still along all the advantages of being safe convenient and faster mode of travel, it's not very uncommon to hear about mishaps related to air travel nowadays.

Over the last few years, fatigue amongpilots and cabin crew has become a genuineconcern in the aviation world. Despitescientific studies showing that fatiguecould jeopardise the safety of air operations, data about the prevalence of fatigue acrossEurope is scarce. With estimates of anapproximate doubling of air traffic by 2020,quantifying this phenomenon becomes ofmajor importance for the aviation world. ${ }^{1}$

According to studies it is found out that fatigue and sleep related problems due to over excursion and circadian rhythm among crew members who are involved in flying. This might strongly related to mishapsand problems that involved safety of the passengers and the aircraft.

\section{Rationale of the study:-}

Literature review has revealed that no research has been done on pilots and other air crew in Pakistan. Therefore, we wanted to investigate the level of fatigue, sleeplessness, insomnia or other health related problems among pilots, other flying and cabin members of airlines operated in Pakistan.

Secondly, it is a part of the curriculum of as a research project for the subject of Community Medicine in $4^{\text {th }}$ academic year of MBBS degree programme.

\section{Objectives of the study:-}

The objectives of the study are to:

1) Assess the level of fatigue among commercial airline crew members of Pakistan.

2) Assess the presence of sleep disorders among commercial airline crew members of Pakistan.

3) Find out the presence of addiction among commercial airline crew members of Pakistan.

4) Identify various health related symptoms among commercial airline crew members of Pakistan.

\section{Literature review:-}

We all know in this era of 21st century people consider air travel/flight travel over other modes of transportation. Because it's faster and less prone to accidents compared to other means of travel. It allows travellers to reach more domestic destinations within few hours. Moreover it is beneficial for economy, plus an additional aid to safety and health. Without air travel multicultural lifestyle and diversity wouldn't exist.

Despite of several advantages, long term air travel has certain drawbacks when it comes to the health of travellers, sleep, fatigue and other healthrelated problems are commonly reported in literature overtime:

Fatigue:- is a physiological state of reduced mental or physical performance capability resulting from sleep loss or extended wakefulness, ration phase or workload mental /physical that can impair a crew member's alertness and ability to safely operate an aircraft or perform safety related duties.

Factors identified as contributors to aircrew fatigue include irregular sleep and work patterns (causing disruption of the circadian rhythm), long duty days, early starts, night flying, multiple sectors and flying into discretion hours ${ }^{(2-5)}$

These are categorized in to various sleep disorders that includes difficulty of sleep onset, sleep maintenance and early morning wakening problems, sleep dissatisfaction, interference of sleep difficulties with daytime functioning, sleep problems noticeablyby others and distresses caused by the sleep difficulties. ${ }^{6}$

\section{Study 1:-}

A studyby Andrew Steptoe done in 2011 indicated 45\% respondents were suffering from clinically relevant level of fatigue. A small proportion of pilots felt that their abilities were compromised by fatigue more than once a month. Fatigue levels are also closely associated with sleep problems and anxiety and depression. These pattern were higher among pilot with higher work index and composite measure of duty hours, sectors flying hours. ${ }^{7}$ 


\section{Study 2:-}

According to this study, nineteen pilots (10 Captains, nine $1^{\text {st }}$ officers) participated in different pattern of flights were included. Before and after each flight participant completed palm-pilot-based psychomotor vigilance task PVT, and self-rated level of fatigue using Samn-Petrlli Fatigue Checklist. A significant main effect on stage of flight was found, sleep self-rated fatigue was $\mathrm{p}<0.05$ only on self-rated fatigue was $\mathrm{p}<0.1$.Hence Flight sector and sleep prior 24 hours is significant predictor of self-rated fatigue. ${ }^{8}$

\section{Study 3:-}

This study states that, although estimates vary but the official statistics tells us that fatigue is involved in least 4-8\% of aviation mishaps and survey of pilot and aircrew revealed that fatigue is an important concern throughout today 24/7 flight operations. ${ }^{9}$

\section{Study 4:-}

This study basically deals with a sample size of 253 pilots operating at Air New Zealand regional and international routes. And $13 \%$ responded were experiencing fatigue from their jobs as pilots, 3 times or more per week. ${ }^{10}$

\section{Study 5:-}

A study done on July 2010 by Thomas and Fequson, and data was collected during 302 normal flights operations.Crew members were asked to provide an estimate of total sleep prior 24 hours total sleep prior $48 \mathrm{~h}$ and total wake time since their last sleep period at the commencement of cruise. Observer used Threat and Error management model a highly standardized and structural method to collect operational performance. Results showed restricted sleep prior to each sector were found to be associated with changes in crews treat to error in management of performance moreover restriction to less than 6hour sleep prior $24 \mathrm{hrs}$ was associated with degraded operational performance and increased error rates also that prior sleep is critical fatigue related variable. ${ }^{11}$

\section{Study 6:-}

In 2011, Runeson carried out a research to access relationship between sleep problem and physiological work situation among pilots.

A group of 354 pilot participated $61 \%$ who are in 2008 responded to questionnaire concerning sleep problems physiological work situation and personal factors plus the length of flights.Results showed low social support was associated with sleep problems in pilot and long travel flights is associated with sleep problems in ${ }^{\text {st }}$ officers. ${ }^{12}$

\section{Methodology:-}

\section{Study design:-}

It is a cross-sectional survey conducted by students of $4^{\text {th }}$ year MBBS of Hamdard College of Medicine \& Dentistry. The study was carried out from January to October 2014 while fieldwork is done between June and September.

\section{Target population/participants:-}

All airline crew members belonging to commercial airline were included to participant. The staff included the cabin crew, flight attendants, captains, co-pilots, hostesses, stewards and cabin managers. The participants were performing their routine flying duties with the relevant job descriptions in the private and public airline companies.

\section{Study Settings:-}

The airline crew members who were on or off duty at Karachi International airport irrespective of the commercial airlines operated by public or private sector were asked participate in the study. A self-administrated questionnairewas distributed to those who agree to participate in the study.

\section{Sample size:-}

The sample size of 150 was targeted. However, 120 respondents agreed to fill the questionnaire. Twelve questionnaires were rejected for incomplete or wrong filling having a total sample size of 108 participants.

\section{Sampling technique:-}

A snow ball sampling method was used to gather the information. A total of 120 questionnaires were collected from aircrew staff within the speculated time frame. 


\section{Instrumentation (The Questionnaire):-}

Keeping in view the study objectives, a questionnaire was made having the following components.

A) Demographic data:-

The questionnaire included questions based on demographic information of participants that included age, sex, work position work experience, details of flying hours and rest time.

B) Insomnia Severity Index ${ }^{13}$ :-

It is designed to assess the nature, severity, and impact of insomnia and monitor treatment response in adults. It domain the questionnaire assesses are morning wakening problems, sleep dissatisfaction,interference of sleep difficulties with daytimefunctioning, noticeablyrelated of sleep problems. 5-point likert scale is used with a content validity of $86.1 \%$ sensitivity and $87.7 \%$ specificity with Cronbach $\alpha=0.90$ and 0.91 respectively.

C) Epworth Sleepiness Scale ${ }^{14}$ :-

The Epworth Sleepiness Scale (ESS) is an effective instrument used to measure average daytime sleepiness. The ESS differentiates between average sleepiness and excessive daytime sleepiness that requires intervention. The client selfrates on how likely it is that he/she would doze in eight different situations. Scoring of the answers is 0-3, with 0 being "would never doze" and 3 being "high chance of dozing". A sum of 10 or more from the eight individual scores reflects above normal daytime sleepiness and need for further evaluation. There is a high level of internal consistency between the eight items in the ESS as measured by Cronbach's alpha, ranging from 0.74 to 0.88 . Numerous studies using the ESS have supported high validity and reliability.

D) Fatigue Severity Scale(FSS) ${ }^{7}$ :-

The Fatigue Severity Scale (FSS) is a method of evaluating the impact of fatigue on the participant and rate the level of fatigue. The questionnaire contains nine statements that rate the severity of the fatigue symptoms having a number from 1 to 7 , based on how accurately it reflects the condition during the past week and the extent to which the person agree or disagree that the statement applies to him/her. A low value (e.g. 1) indicates strong disagreement with the statement whereas a high value (e.g. 7) indicates strong agreement.

E) Counter measures for alertness and addiction:-

The remaining questions were asked to find out the counter measures to overcome any fatigue and sleep-related problems. It further explores to indentify the type of addition the participant is suffering.

\section{Inclusion and exclusion criteria:-}

All working air crew staff irrespective of their gender age and sex were included,

Grounded members, sick and members with busy day schedule and cannot commit required time to fill the questionnaire were excluded.

\section{Data analysis:-}

Data was entered and analysed using SPSS for windows version 20. Frequencies and percentages were taken out for descriptive variables whereas cross tabulations are aimed to be done between with categorical variables.Chi square test was used as test of significance and $\mathrm{P}<0.05$ was taken as significance level.

\section{Ethical considerations:-}

The target population was approached and the whole procedure and the objectives of the study, the questionnaire was explained to them. The questionnaire was only given to fill only after their verbalconsent. All aircrew members participated voluntarily in this research.

The study was ethically approved by the Ethical Review Committee Hamdard College of Medicine and Dentistry to carry out our research. The name of any of the member aircrew staff was kept completely confidential.

\section{Results:-}

Descriptive:-

About 150 questionnaires were distributed, 120 were returned and collected. A total of 108 respondents were included in the study, out of which 86 were female crew members and 22 were male members as shown in Figure no 1 .

The mean age was $32.41 \pm 7.0$ years. The majority of the respondents were of ages between 20-30 years. About $70 \%$ had 1-10 years of work experience. Figure no 5 most of the crew members were married. The average flying hours per week was found to be $26.81 \pm 13.1$ hours 


\section{Insomnia Severity Index Scores:-}

While using insomnia severity index score we found out that only $9.3 \%$ showed no clinically significant insomnia, on the other hand $51.9 \%$ showed sub threshold insomnia,31.5\% showed clinically significant insomnia (moderate) and $7.4 \%$ had complains of severe clinically significant insomnia. Insomnia a major problem with members of crew.

\section{Epworth Sleepiness Scale:-}

Day time sleepiness was assessed by Epworth Sleepiness scale score amongst our crew members. It showed remarkable increase in daytime sleepiness to a significant value which should be pondered on.

\section{Fatigue Severity Scale:-}

In order to evaluate fatigue a common complaint we used fatigue severity scale about $60 \%$ were sufferers of clinically significant fatigue.

We also accessed any other measures taken to keep them alert. Shown in Table no.4.Here 51 used caffeinated drinks,27 used napping pre/after flight,31 napping during flight,17 taking stimulants for alertness,5 were oncaffeinesupplements whereas 6 used hypnotic drugs.

Others habits common in aircrew members were also accessed,. Represented by figure 12 .More than 40\% respondents' claim that they never smoked, about $28 \%$ smoked daily, $26 \%$ smoked occasionally and $15 \%$ were found to be ex-smokers.

The participants were found be addicted to alcohol. according to Figure no. 13,50\% claimed they don't drink alcohol $35 \%$ were drink alcohol occasionallywhile $18 \%$ on special occasions and only $8 \%$ were in habit of consuming alcohol regularly...

Their life style was also assessed, and most of them $57 \%$ used to exercise regularly, (31\% of them used to do it 5days/week) and had a healthy life style.

We evaluated few symptoms to rule out other common diseases or symptoms, results showed a significant association with back pain in $12.8 \%, 7.7 \%$ swollen ankles. $7.4 \%$ earache, along with other symptoms. Table no:3

\section{Graphical:-}

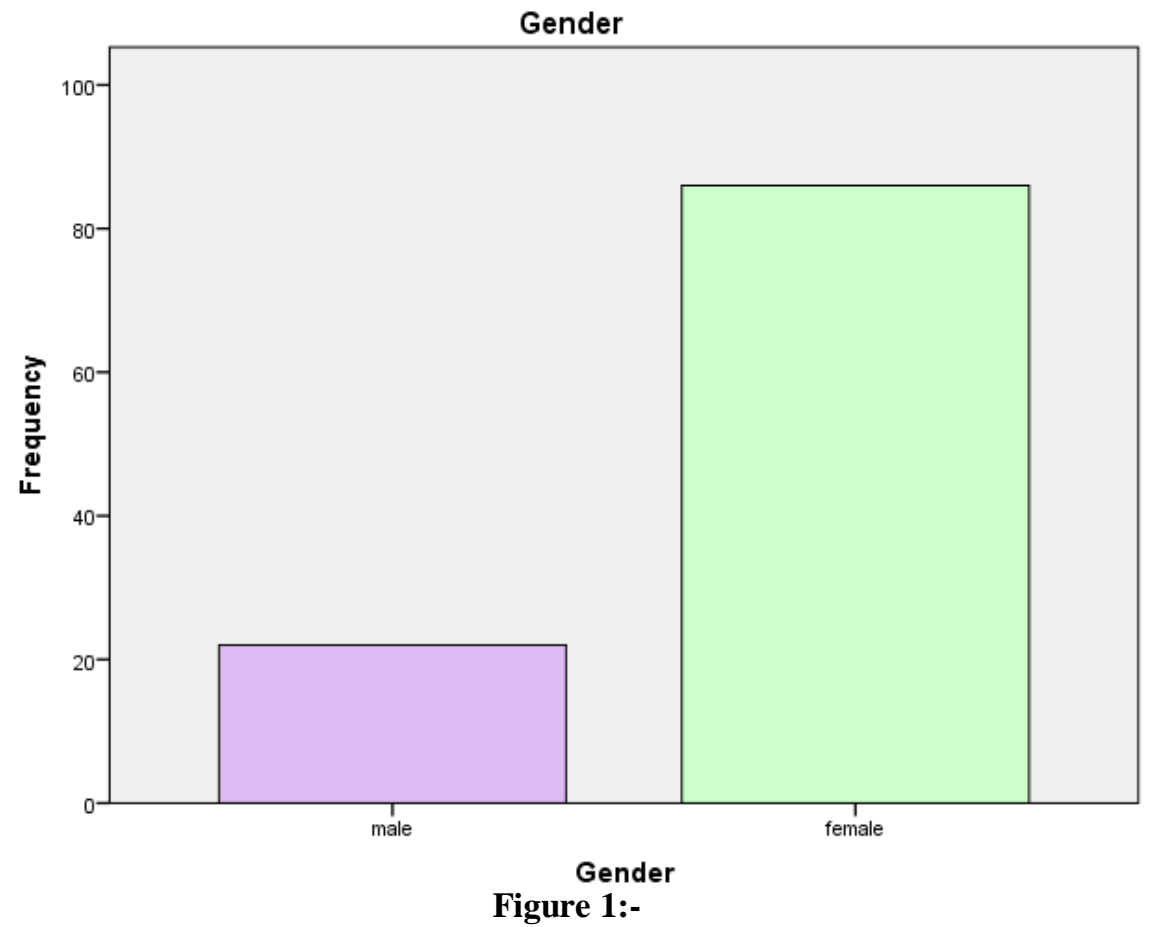




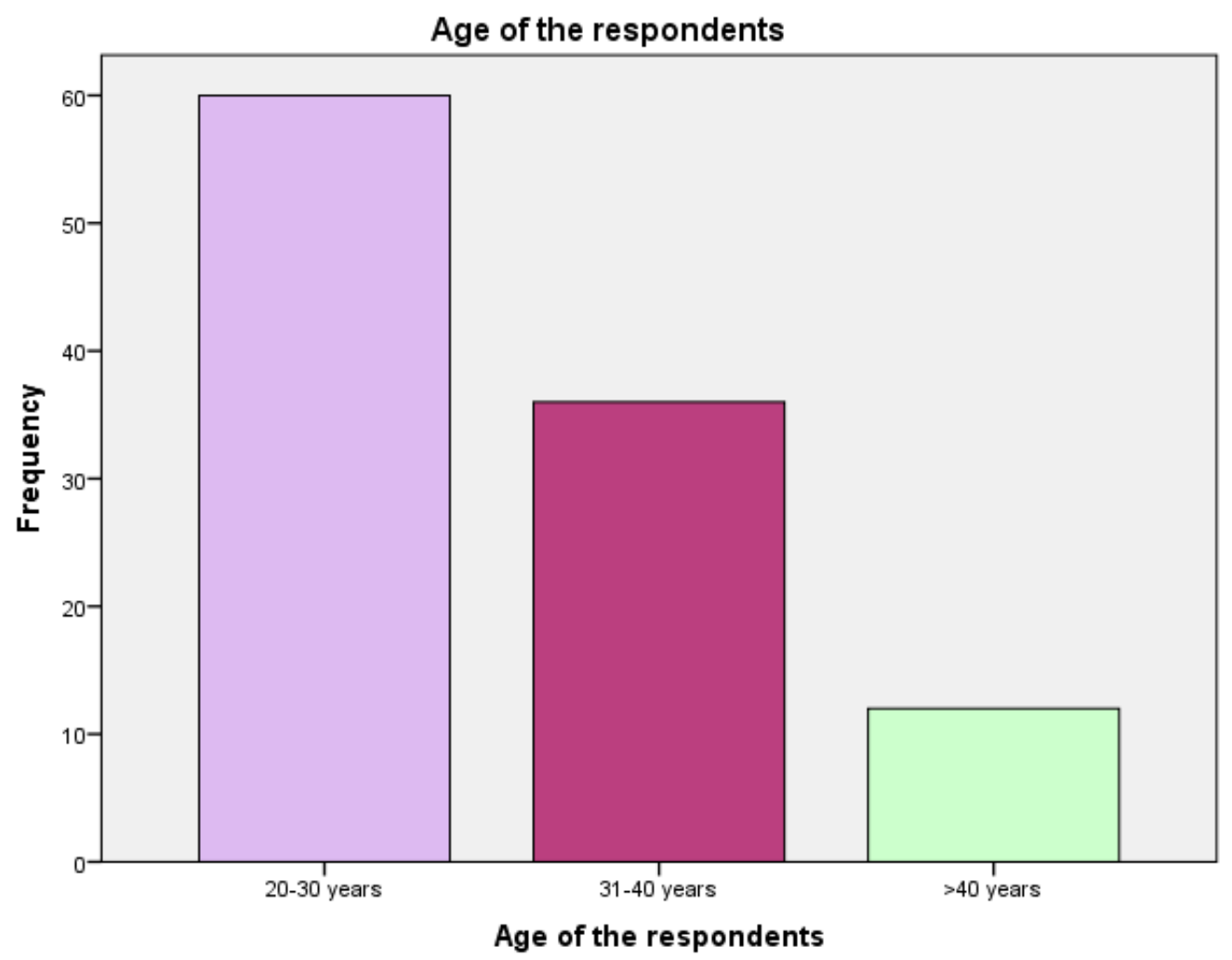

Figure 2:-

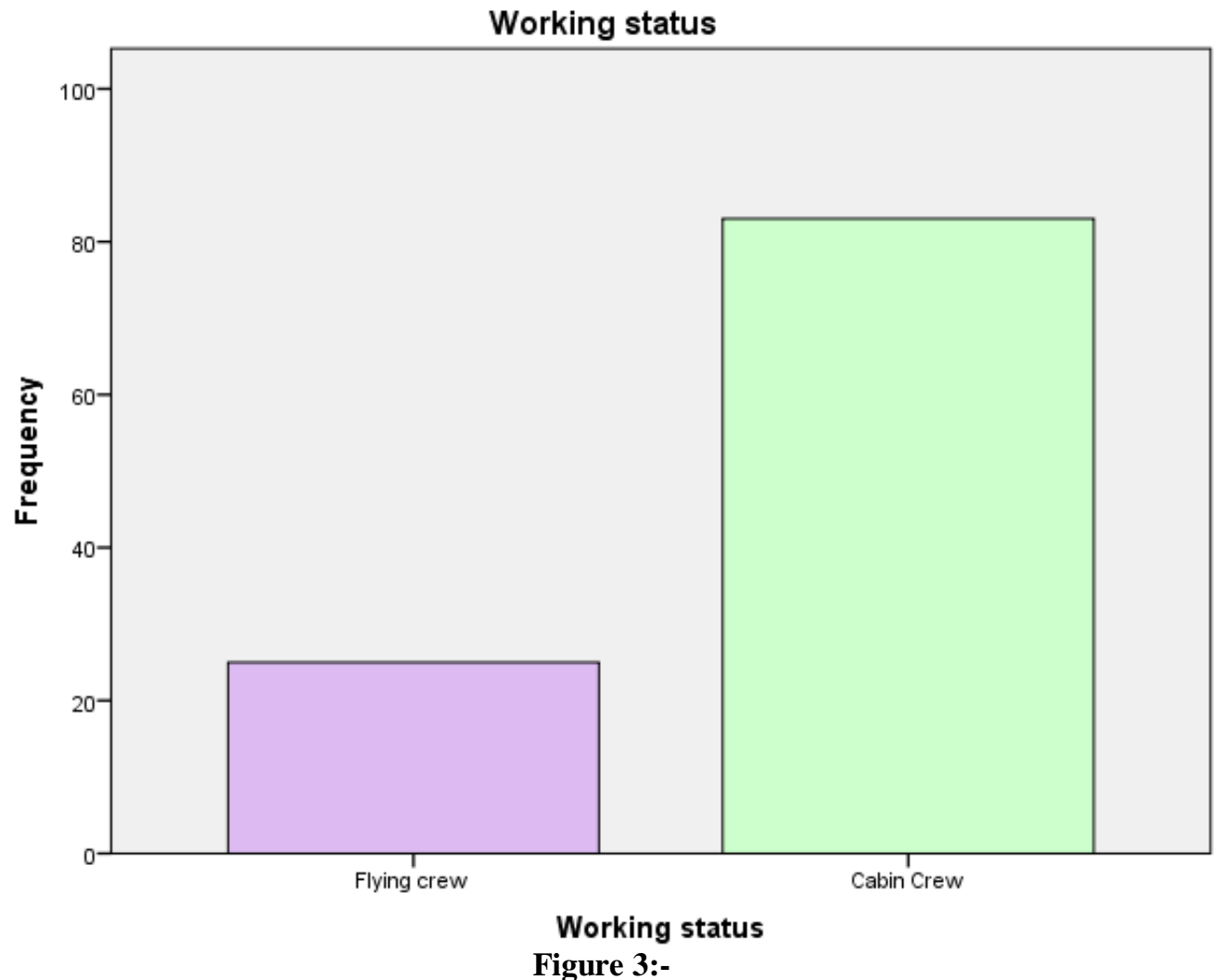




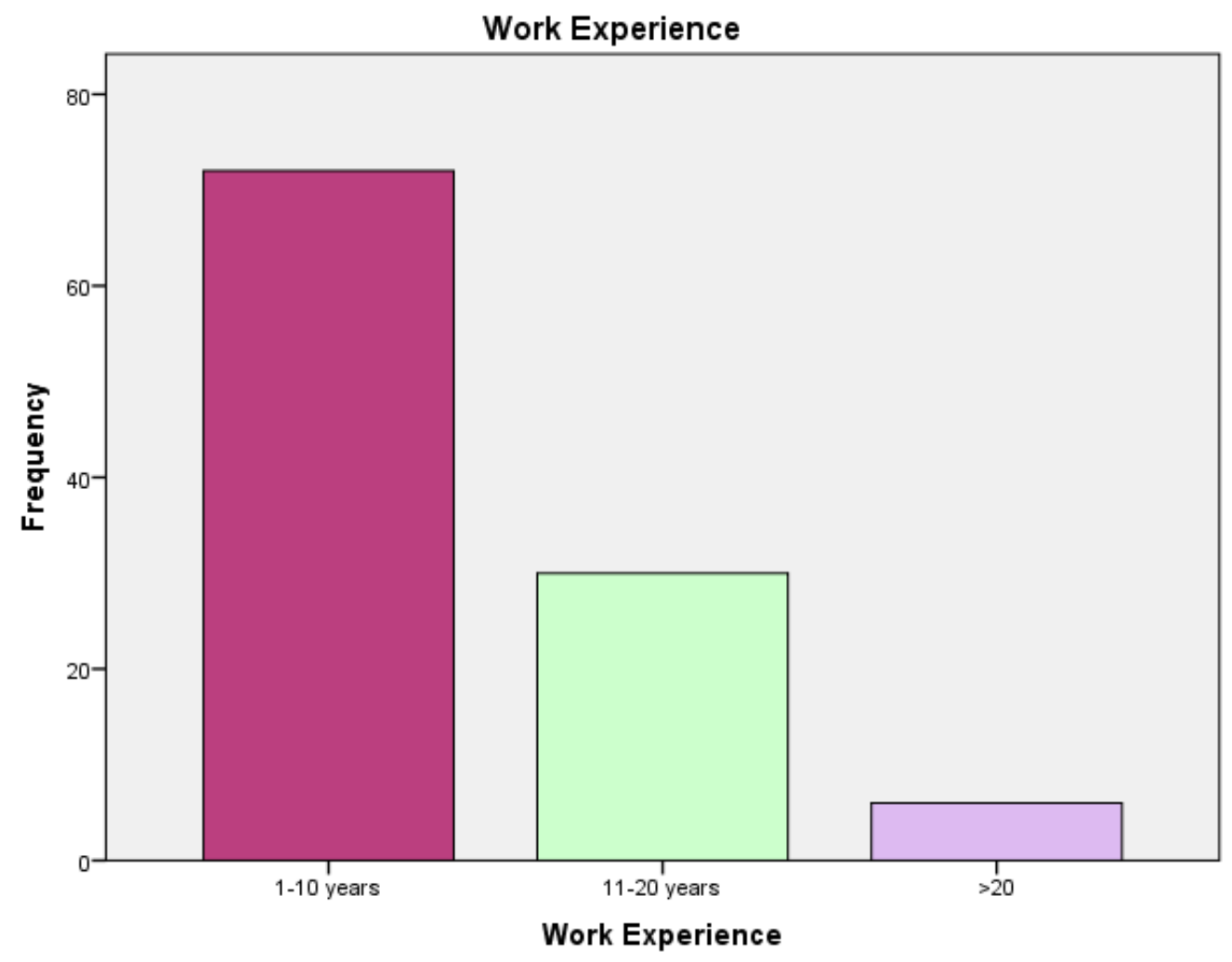

Figure 4:-

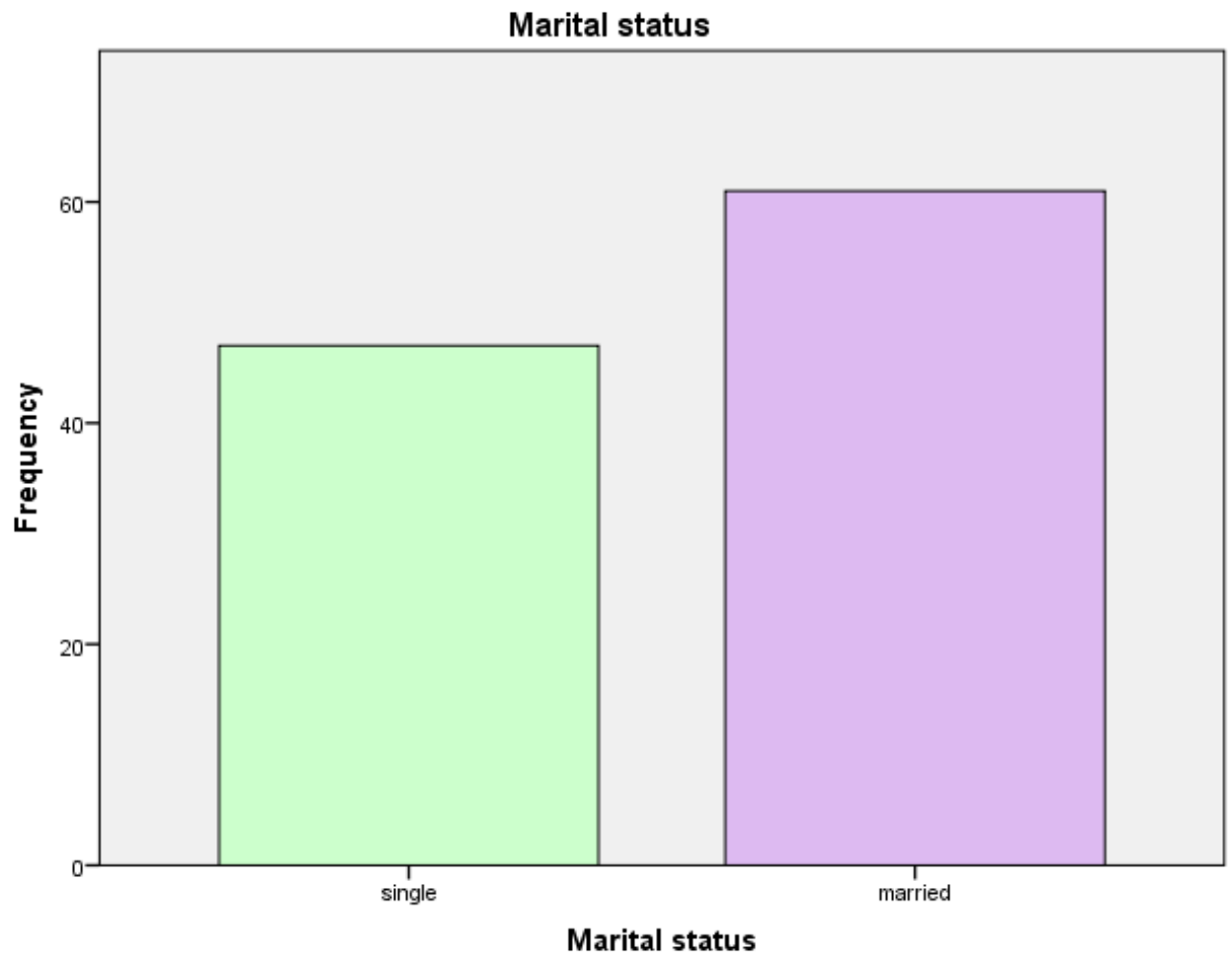

Figure 5:- 


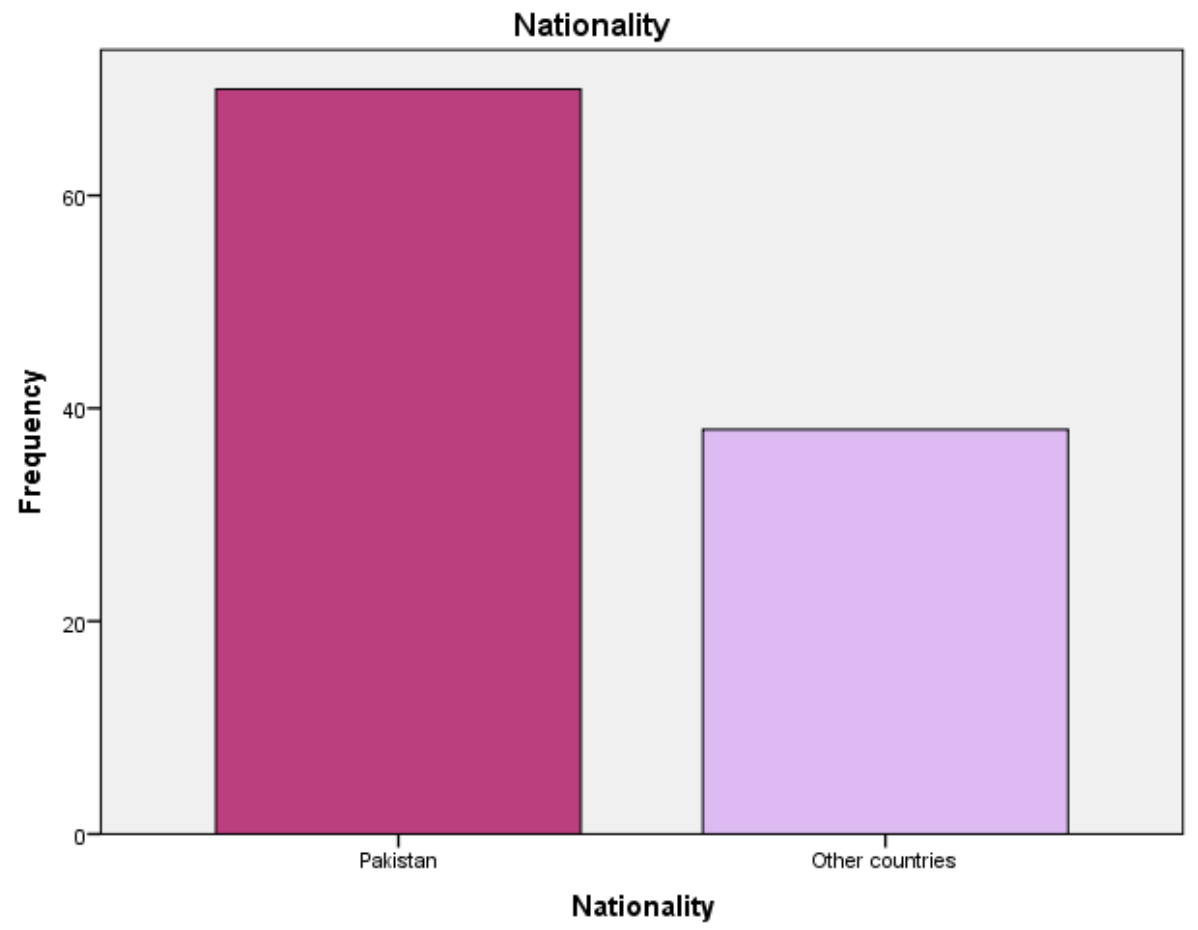

Figure 6:-

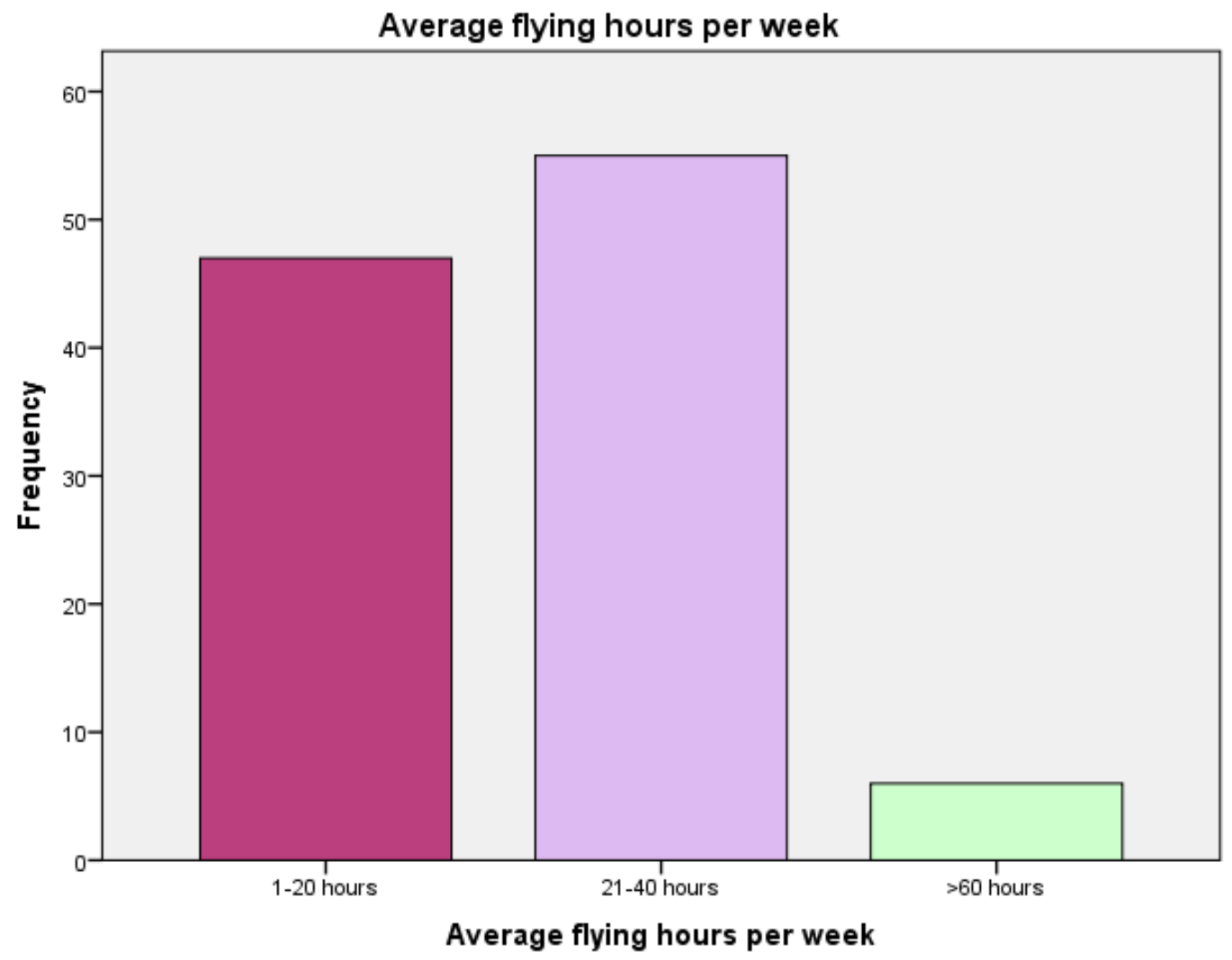

Figure 7:- 


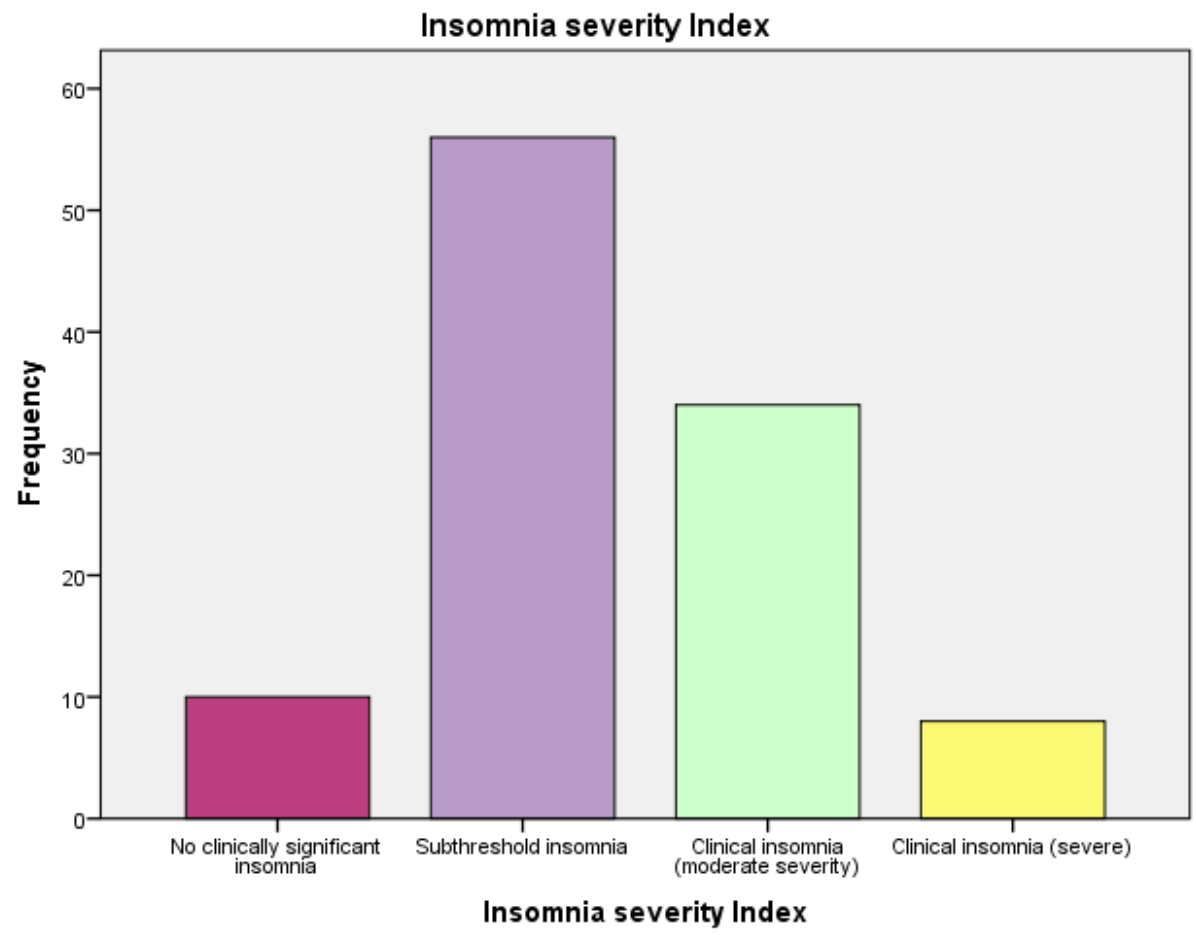

Figure 8:-

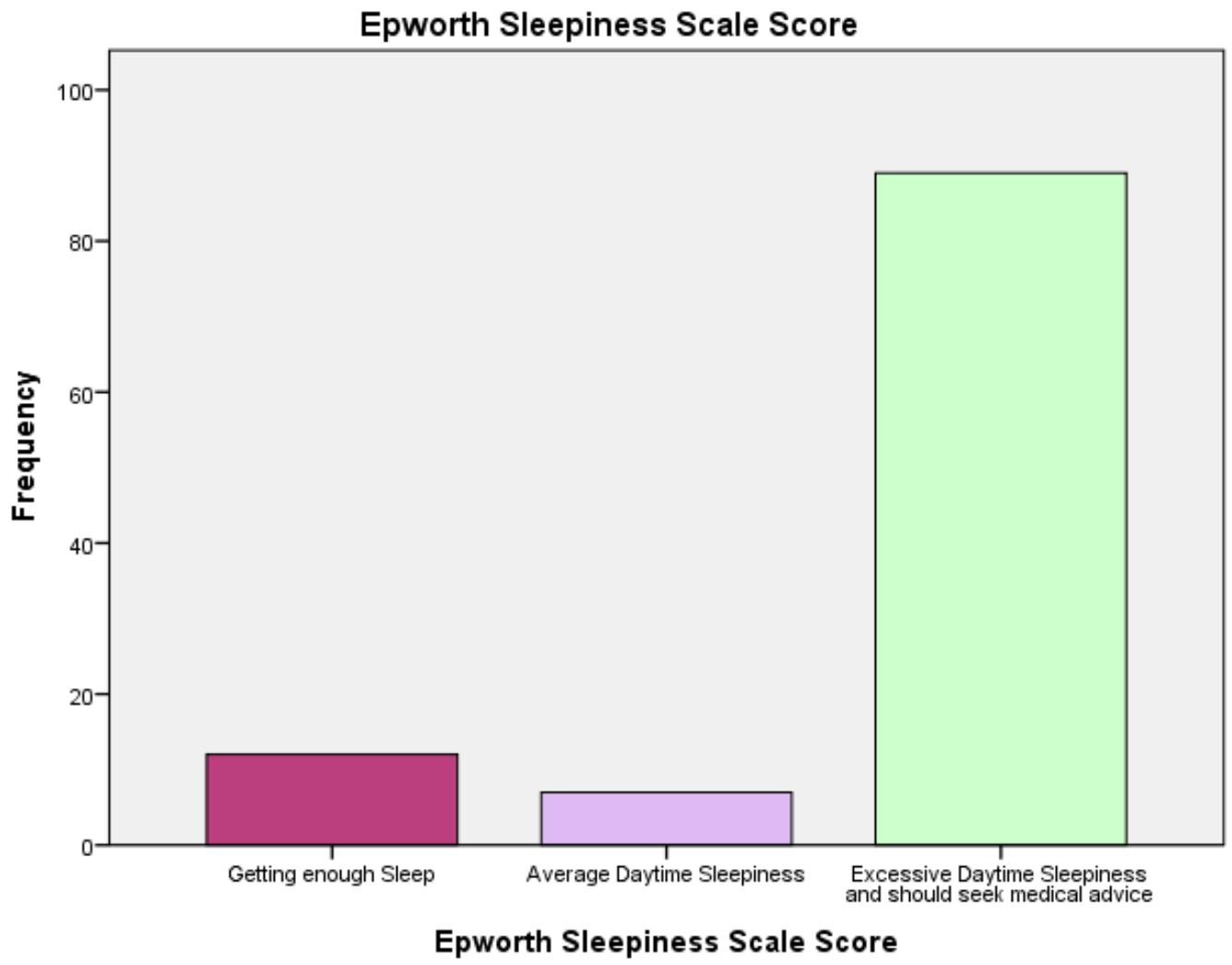

Figure 9:- 


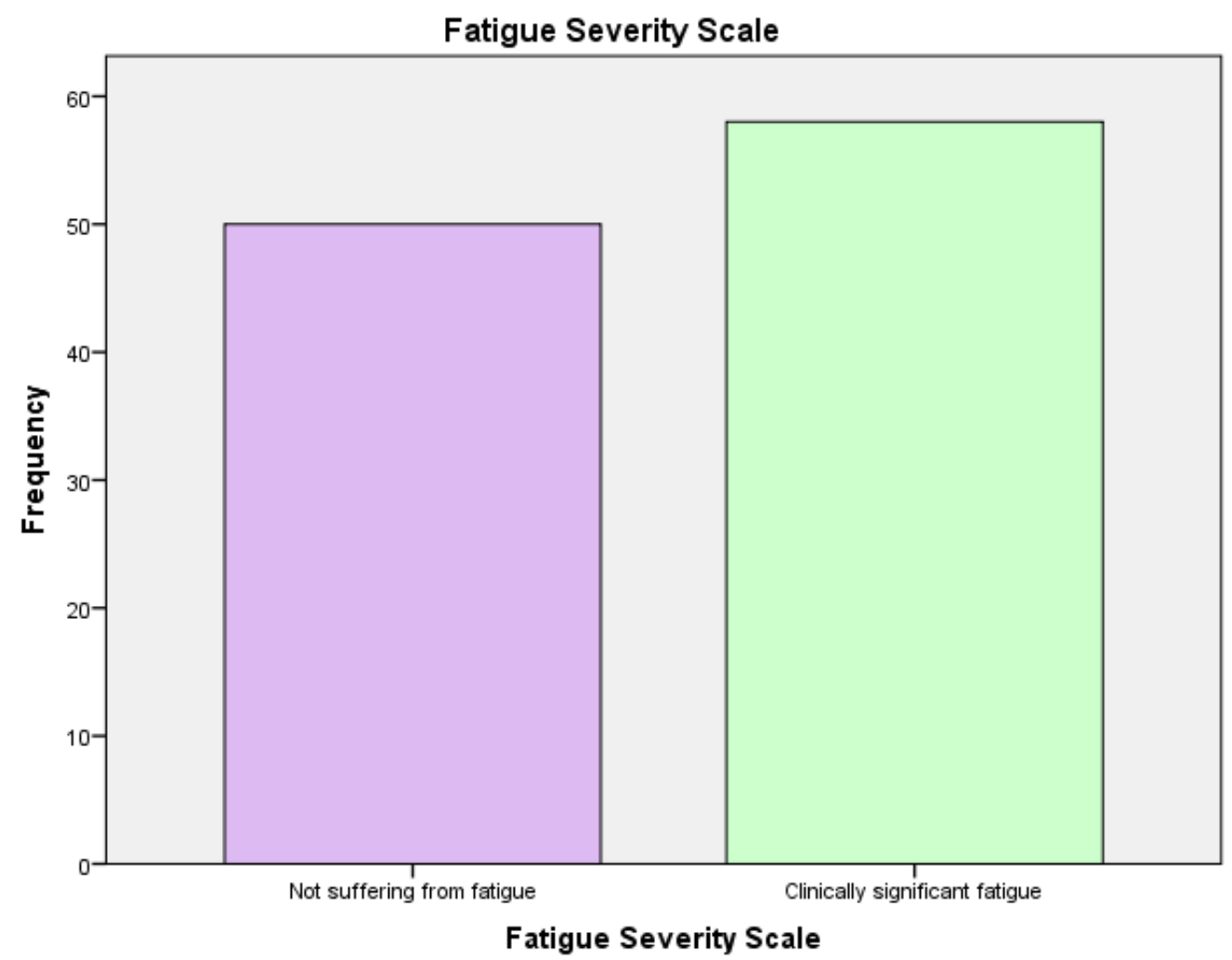

Figure 10:-

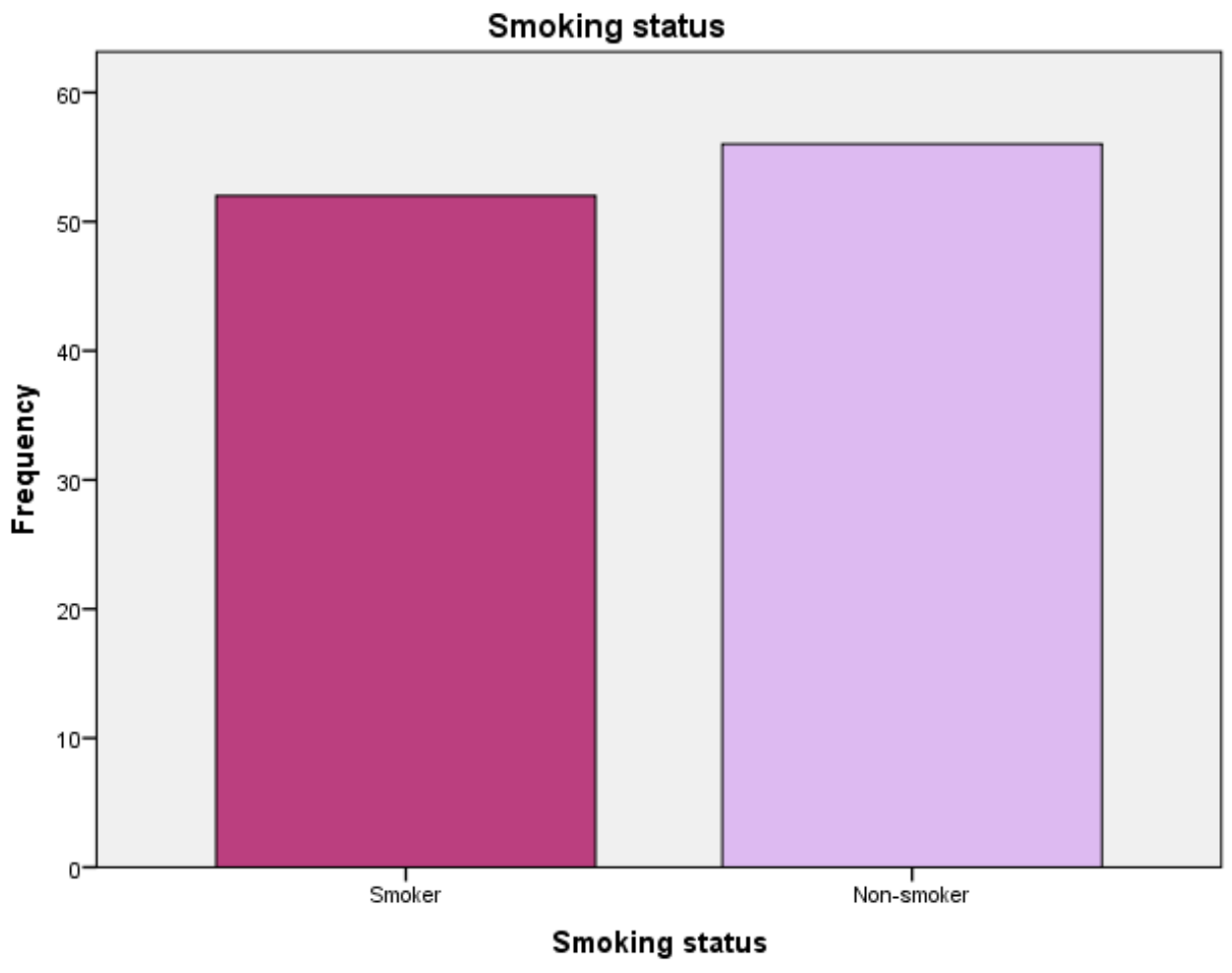

Figure 11:- 


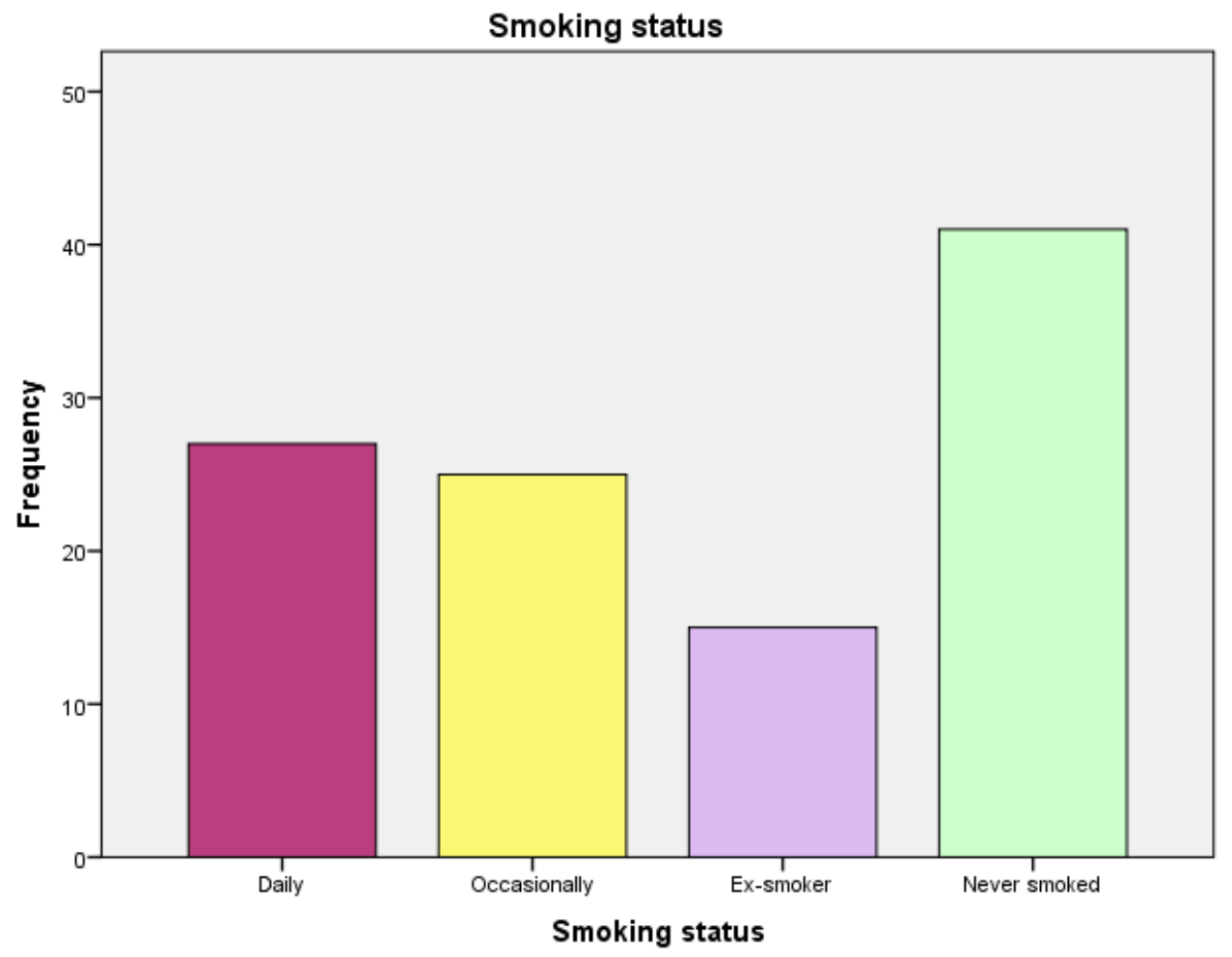

Figure 12:-

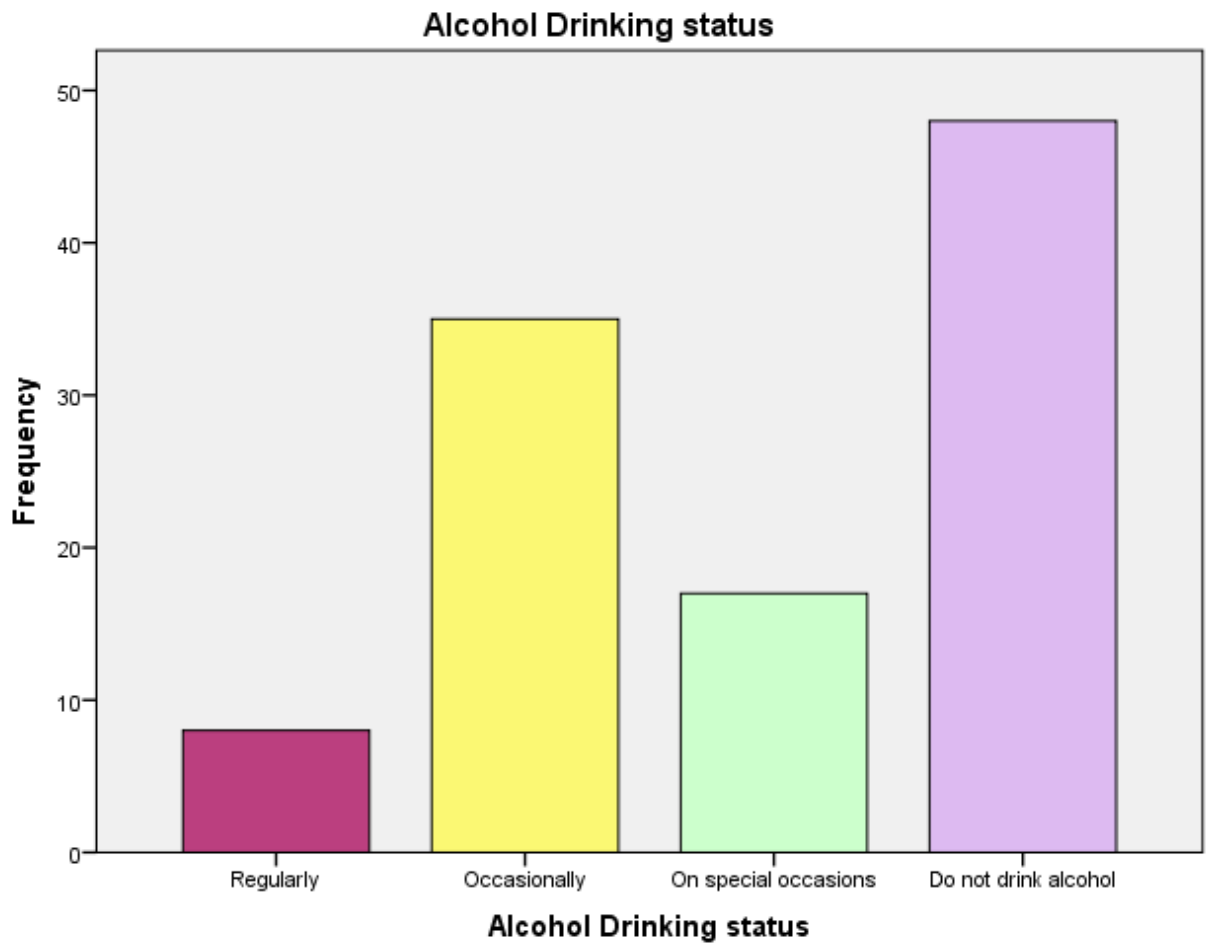

Figure 13:- 


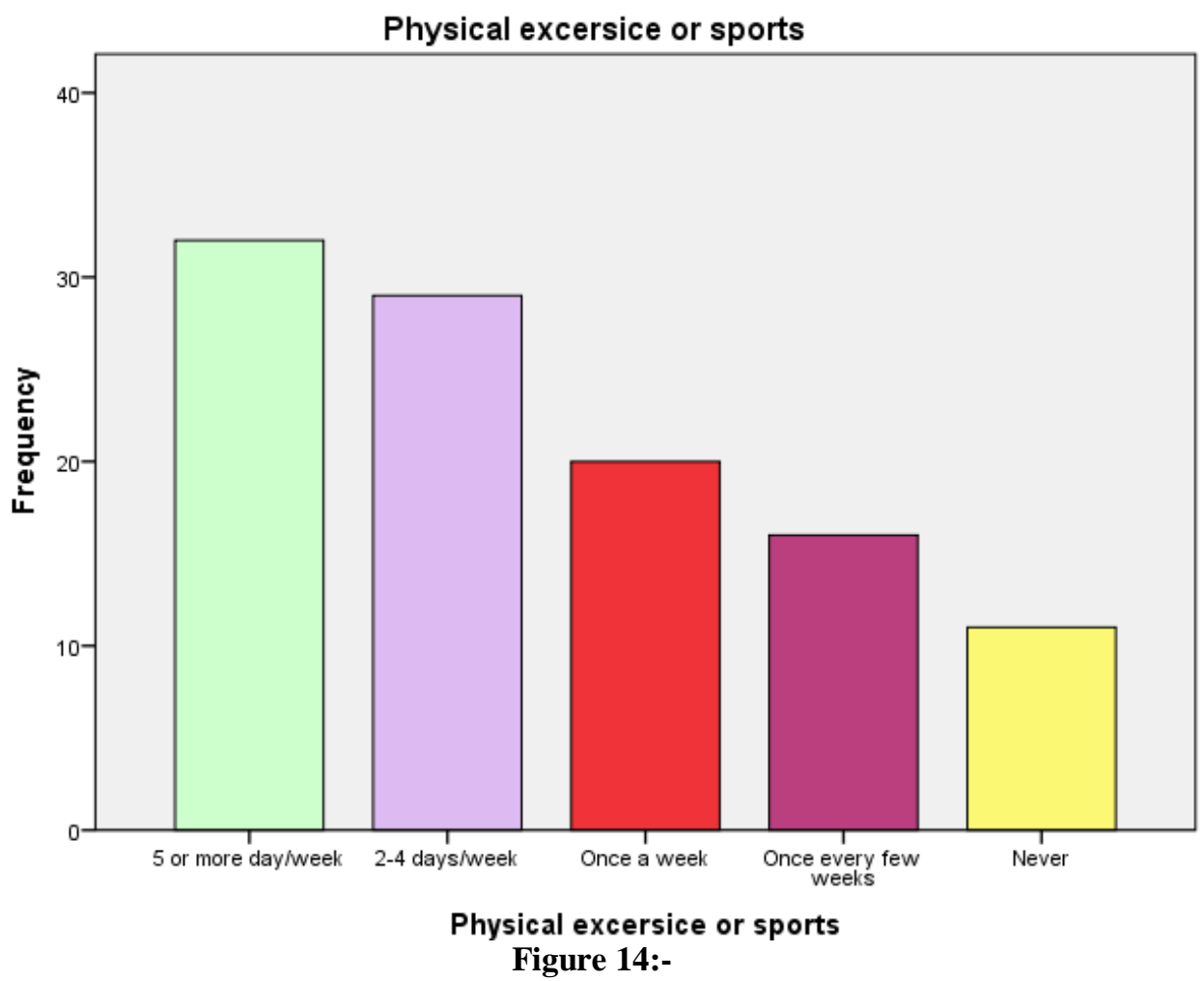

Table 1:- Cross tabulation of Daytime Sleepiness and years of experience.

\begin{tabular}{|c|c|c|c|c|c|}
\hline \multicolumn{5}{|c|}{ Epworth Sleepiness Scale Score } & \multirow[b]{3}{*}{$\begin{array}{c}\text { Chi-square } \\
\text { (P value) }\end{array}$} \\
\hline & \multicolumn{3}{|c|}{ Work Experience } & \multirow[t]{2}{*}{ Total } & \\
\hline & $1-10$ years & $11-20$ years & $>20$ & & \\
\hline \multirow[t]{2}{*}{ Getting enough Sleep } & 9 & 2 & 1 & 12 & \\
\hline & $12.5 \%$ & $6.7 \%$ & $16.7 \%$ & $11.1 \%$ & \multirow{6}{*}{$\begin{array}{c}9.0 \\
(0.06)\end{array}$} \\
\hline \multirow[t]{2}{*}{ Average Daytime Sleepiness } & 4 & 1 & 2 & 7 & \\
\hline & $5.6 \%$ & $3.3 \%$ & $33.3 \%$ & $6.5 \%$ & \\
\hline \multirow{2}{*}{$\begin{array}{l}\text { Excessive Daytime Sleepiness and } \\
\text { should seek medical advice }\end{array}$} & 59 & 27 & 3 & 89 & \\
\hline & $81.9 \%$ & $90.0 \%$ & $50.0 \%$ & $82.4 \%$ & \\
\hline \multirow[t]{2}{*}{ Total } & 72 & 30 & 6 & 108 & \\
\hline & $100.0 \%$ & $100.0 \%$ & $100.0 \%$ & $100.0 \%$ & \\
\hline
\end{tabular}

Table 2:- Cross tabulation of Daytime Sleepiness and Working status.

\begin{tabular}{|c|c|c|c|c|}
\hline \multicolumn{4}{|l|}{ Epworth Sleepiness Scale Score } & \\
\hline \multirow[t]{2}{*}{ Epworth Sleepiness Scale Score } & \multicolumn{2}{|c|}{ Working status } & \multirow[t]{2}{*}{ Total } & \\
\hline & Flying crew & Cabin Crew & & Chi square $(\mathrm{P})$ value \\
\hline \multirow{2}{*}{ Getting enough Sleep } & 5 & 7 & 12 & \\
\hline & $20.0 \%$ & $8.4 \%$ & $11.1 \%$ & \\
\hline \multirow[t]{2}{*}{ Average Daytime Sleepiness } & 4 & 3 & 7 & $8.1 \mathrm{P}$ value 0.017 \\
\hline & $16.0 \%$ & $3.6 \%$ & $6.5 \%$ & \\
\hline \multirow{2}{*}{$\begin{array}{l}\text { Excessive Daytime } \\
\text { Sleepiness and should seek } \\
\text { medical advice }\end{array}$} & 16 & 73 & 89 & \\
\hline & $64.0 \%$ & $88.0 \%$ & $82.4 \%$ & \\
\hline \multirow[t]{2}{*}{ Total } & 25 & 83 & 108 & \\
\hline & $100.0 \%$ & $100.0 \%$ & $100.0 \%$ & \\
\hline
\end{tabular}


Table 3:- Frequencies of health related symptoms (More than one response was allowed).

\begin{tabular}{|c|c|c|c|c|}
\hline \multirow[t]{2}{*}{ Symptoms } & \multicolumn{4}{|c|}{ Symptom frequencies } \\
\hline & & $\mathrm{N}$ & percent & Percent cases \\
\hline & Difficulty in sleeping & 51 & $13.0 \%$ & $47.2 \%$ \\
\hline & Feeling tired for no apparent reason & 30 & $7.7 \%$ & $27.8 \%$ \\
\hline & Backache or pain in the back & 50 & $12.8 \%$ & $46.3 \%$ \\
\hline & cough catarrh or phlegm & 19 & $4.8 \%$ & $17.6 \%$ \\
\hline & A sore throat & 14 & $3.6 \%$ & $13.0 \%$ \\
\hline & Heartburn, wind or indigestion & 11 & $2.8 \%$ & $10.2 \%$ \\
\hline & A cold or flu & 17 & $4.3 \%$ & $15.7 \%$ \\
\hline & Earache or discomfort in ear & 29 & $7.4 \%$ & $26.9 \%$ \\
\hline & Nervy, tensed or depressed & 19 & $4.8 \%$ & $17.6 \%$ \\
\hline & Diarrhoea & 16 & $4.1 \%$ & $14.8 \%$ \\
\hline & Rashes, itches or other skin troubles & 13 & $3.3 \%$ & $12.0 \%$ \\
\hline & Night sweats & 10 & $2.6 \%$ & $9.3 \%$ \\
\hline & Toothache or other troubles with the gums. & 7 & $1.8 \%$ & $6.5 \%$ \\
\hline & Nausea or vomiting. & 6 & $1.5 \%$ & $5.6 \%$ \\
\hline & Dizziness or giddiness & 12 & $3.1 \%$ & $11.1 \%$ \\
\hline & Shortness of breath & 15 & $3.8 \%$ & $13.9 \%$ \\
\hline & Palpitations & 13 & $3.3 \%$ & $12.0 \%$ \\
\hline & Pain in chest & 18 & $4.6 \%$ & $16.7 \%$ \\
\hline & Hot flushes & 10 & $2.6 \%$ & $9.3 \%$ \\
\hline & Swollen ankles & 30 & $7.7 \%$ & $27.8 \%$ \\
\hline & Others & 2 & $0.5 \%$ & $1.9 \%$ \\
\hline & Total & 392 & $100.0 \%$ & $363.0 \%$ \\
\hline
\end{tabular}

Table 4:- Frequencies of Counter measures taken for alertness (More than one response was allowed).

\begin{tabular}{|c|c|c|c|c|}
\hline \multicolumn{2}{|r|}{ Responses } & & & \\
\hline \multicolumn{2}{|c|}{ Counter Measures taken } & $\mathrm{N}$ & Percent & Percent of Cases \\
\hline & drinking caffeinated drinks & 51 & $37.2 \%$ & $48.1 \%$ \\
\hline & napping in preparation/after a flight & 27 & $19.7 \%$ & $25.5 \%$ \\
\hline & napping in flight & 31 & $22.6 \%$ & $29.2 \%$ \\
\hline & taking stimulants to keep you alert & 17 & $12.4 \%$ & $16.0 \%$ \\
\hline & taking caffeine supplements & 5 & $3.6 \%$ & $4.7 \%$ \\
\hline & taking hypnotics to help with sleep & 6 & $4.4 \%$ & $5.7 \%$ \\
\hline Total & 137 & $100.0 \%$ & $129.2 \%$ & \\
\hline
\end{tabular}

\section{Discussion:-}

The present survey confirms that fatigue is common among aircrew members, including pilots which could be dangerous. A common indicator of the problem is thatthe fatigued aircrews are more prone to fall asleep or experience episodes of micro-sleep during the flight. This is quite obvious by our results. Since the questionnaire tested various parameters of sleep problems using different scales, the presence of insomnia and day time sleepiness was significantly reported in our study.

We feel that fatigue and sleeplessness are major factors that can impair crew members' alertness and their ability to operate aircraft safely. Comparing it to the study by Professor Andrew Steptoe, this stated that the ability of pilots was compromised by fatigue. Moreover fatigue and sleeplessness together are important contributing factors as one the studies have reported that $4-8 \%$ aviation mishaps are related to fatigue however, other contributing factors should also be kept in mind. ${ }^{11}$ These results of the present study also help us access the useful measures one can take for optimum performance of aircrew staff. 
Now let's consider a study that compared sleep with performance suggesting that restriction to less than 6 hours sleep prior 24 hours was associated with degraded operational performance and increased error rates also that prior sleep is a critical fatigue related variable. ${ }^{11}$

Hence fatigue and sleeplessness are two important, yet closely related factors together contributing to work efficiency of crew member in addition, positive results such as increase in daytime sleepiness to significant level plus insomnia severity and fatigue pattern from results a highly indicate that this is a matter of concern and proper measures should be taken to ensure health of members of aircrew staffs. Their health and alertness play a major role on their performances and the safety of flights.

This study being the first of its kind carried out in Pakistan on local population, it is a first step towards closing the gap between operational reality - as assessed by airline pilots - and official statistics that is available (if any). The study has successfully captured this phenomenon quantitatively and has drawn its attention for the potential impact on flight safety.

\section{Conclusion:-}

The present study shows that aircrew fatigue has become a reality in Pakistan's commercial airlines. The consequences results in a larger proportion with insomnia and day time sleepiness. It is more wide-spread than expectedand at the same time it may significantlyunder-reported by personals themselves.

More data collection among air crew willbe necessary to get a full picture on theprevalence fatigue and sleep related consequences that can have an impact on the safety ofairline operations and their passengers. This study is a first step into thatdirection.

\section{Recommendation:-}

1. Since fatigue has been shown to be a hazard in commercial flight operations especially among pilots, the management of the airline companies should ensure implementation regarding "rest". They should identified requirements for "restful sleep"

2. Reviews of working activities, hours of service/rest regulations, and airline company scheduling policies are needed to correct the existing systemic problems.

3. Enhanced pilot training is also needed to prevent fatigue, and to recognize it when it occurs so that effective countermeasures can be employed. By doing so will help insure that pilots fly adequately rested and alert thereby improving flying safety.

4. As the stresses of flying, or indeed of any activity, consume energy. This energy is derived from oxygen and from blood sugar. The pilot is unwise to fly for too long without eating. His blood sugar will be low, that is, his energy reserve will be low. Reactions will be sluggish and efficiency will be impaired. It is recommended asa good precaution to carry a nutritious snack on long flights.

5. Pre and postflight countermeasures and strategies may be adopted. This include the use of short acting hypnotics may improve sleep and alertness.

6. Strategies for Optimizing Sleep Opportunities may also be used by the aircrew. This includes:

* When possible, wake up and go to bed at the same time everyday to avoid circadian disruptions.

* If possible, establish a consistent and comforting bedtime routine (e.g., reading, taking a hot shower, and then going to bed).

* Perform aerobic exercise every day, but not within $2 \mathrm{~h}$ of going to bed.

- Make sure the sleeping quarters are quiet, totally dark, and comfortable. For this to work, day workers should be housed separately from night workers.

* Keep the sleep environment cool $\left(\sim 26^{\circ} \mathrm{C}\right.$ if you are covered).

* Move the alarm clock out of sight so you can’t be a clock watcher.

* Avoid caffeine in drinks and other forms during the afternoons/evenings.

* Don't use alcohol as a sleep aid (it may make you sleepy, but you won't sleep well).

* Avoid cigarettes or other sources of nicotine right before bedtime.

* Don't lie in bed awake if you don't fall asleep within $30 \mathrm{~min}$ - instead, leave the bedroom and do something relaxing and quiet until you are sleepy.

7. Alertness enhancing medications are one option for sustaining the wakefulness of flight crews during extended missions in which adequate crew rest is not possible. Needless to say, these compounds should not be 
considered a replacement for adequate crew rest planning and they should never be considered a substitute for restorative sleep.

\section{References:-}

1. European Cockpit Association. Pilot fatigue Barometer. Available from: https://www.eurocockpit.be/sites/default/files/eca_barometer_on_pilot_fatigue_12_1107_f.pdf accessed on October 21, 2014.

2. Jackson CA \& Earl L (2006) Prevalence of fatigue among commercial airline pilots. Occupational Medicine 56:263-268.

3. Caldwell J, et al. (2009) Fatigue Countermeasures in Aviation. Aviation, Space, Environmental Medicine:2959.

4. Spencer MB \& Robertson KA (2007) Aircrew fatigue: a review of research undertaken on behalf of UK Civil Aviation Authority. CAA Paper 2005/04. .

5. Powell DM, Spencer MB, Holland D, Broadbent E, \& Petrie KJ (2007) Pilot fatigue in short-haul operations: effects of number of sectors, duty length, and time of day. Aviation, Space and Environmental Medicine 78(7):698-701.

6. Haghighi KS, Khazaee S, Aminian O, Momeni P. Evaluation of sleep disorders in flight crew and ground staff worker in Iran private flight airline World Association Of Sleep Medicine - 5th World Congress on Sleep Medicine September 28-02 October, 2013, Valencia Spain

7. Steptoe A, Sophie Bostock S. A survey of fatigue and well-being among commercial airline pilots. UCL Psychobiology Group, Department of Epidemiology and Public Health, London.

8. 8..Petrilli RM, Roach GD, Dawson D, Lamond N.The sleep, subjective fatigue, and sustained attention of commercial airline pilots during an international pattern.Chronobiol Int. 2006;23(6):1357-62.

9. 9.Caldwell JA. Fatigue in aviation.Travel Med Infect Dis. 2005 May;3(2):85-96

10. 10.Petrie KJ, Powell D, Broadbent E.Fatigue self-management strategies and reported fatigue in international pilots.Ergonomics. 2004 Apr 15;47(5):461-8.

11. 11.Thomas MJ, Ferguson SA.Prior sleep, prior wake, and crew performance during normal flight operations..Aviat Space Environ Med. 2010 Jul;81(7):665-70.

12. 12.Runeson R, Lindgren $\mathrm{T}$, Wahlstedt K.Sleep problems and psychosocial work environment among Swedish commercial pilots.Am J Ind Med. 2011 Jul;54(7):545-51.

13. 13.Morin, G Belleville, L Belanger, H Ivers. The Insomnia Severity Index: Psychometric Indicators to detect Insomnia Cases and Evaluate Treatment Response. SLEEP 2011: 34(5): 601—608.

14. 14.Johns, M.W. The Epworth Sleepiness Scale: The Official Website of the Epworth Sleepiness Scale: http://epworthsleepinessscale.com/about-epworth-sleepiness/. 